\title{
Like Sustenance for the Masses: Genre Resistance, Cultural Identity, and the Achievement of Like Water for Chocolate
}

\author{
Ellen Puccinelli \\ Oak Grove, Louisiana
}

\begin{abstract}
With that meal it seemed they had discovered a new system of communication...
\end{abstract}

Laura Esquivel's 1989 Mexican novel Like Water for Chocolate, neither translated into English nor published in the United States until 1992, was both an American bestseller and the basis for an acclaimed motion picture. Interestingly, though, Esquivel's work also seems to be receiving glimmers of the type of critical attention generally reserved for less "popular" works. Two particular critical studies composed in English, one by Kathleen Glenn and the other by Cecelia Lawless, have been devoted entirely to Chocolate, and both of the scholar/authors grace the faculties of reputable American institutions of higher learning. 1 As a student whose academic experience has been replete with elitist attitudes and expressions of disdain for anything that smacks of an appeal to the masses, I was intrigued by Chocolate for this very reason; in a world where scholarly boundaries seem unalterably fixed, a work that appears capable of crossing these rigid lines is, in my opinion, both rare and admirably refreshing. In my studies, I have often hoped for more communication between "popular" and "scholarly" literature; Esquivel's novel provides not only opportunities for this dialogue but for other cross- 
genre discussions as well.

Significantly, both Glenn and Lawless remark on Chocolate's multigeneric character. Lawless opens her study with the following observation:

Laura Esquivel has written an unclassifiable work, which simultaneously breaks and brings together boundaries of genre so as to concoct something new in Mexican literature. Como agua para Chocolate. . is a mixture of recipe book, how-to household book, sociopolitical and historical document of the Mexican revolution, psychological study of male/female as well as mother/daughter relations, an exploration into gothic realms, and ultimately, an extremely readable novel. 2

She later points out that, "In Mexican bookstores Chocolate appears on the shelves with bestsellers and in the area designated for cookbooks."3 Glenn, too, identifies "multiple instances of rulebreaking and border-crossing," stating that, in the novel, "Generic divisions are undone, as cookbook and romance, the culinary and the erotic, mingle,"4 but she goes a step further, noting the scholarly/popular dichotomy and terming Esquivel's work a "hybrid novel" because it includes traits usually associated with both "best sellers and objects of academic study." 5

The novel's barrier-crossing nature, however, does not extend to its cultural boundaries. While Esquivel's work is decidedly multigeneric, it is also a product of its author's Mexican culture, which in turn is part of the larger body of Latin American literature; still more specifically, Chocolate belongs to the segment of this literature composed by women. In addition to examining the ways in which Esquivel defies definitions and rules, then, it is important to look at the ways in which she fits into the literary tradition in which she finds her origins.

"Women have," according to Amy Kaminski, ". . . been writing since the earliest days of colonization" in Latin American countries; but, Kaminski also states, "the story ... of Latin American literature does not mention the names of the prominent female authors in their history."6 Maureen E. Shea, too, believes that, "Whether oral or written, the voices of women in Latin America have generally been ignored, misrepresented, ridiculed, or silenced by the male-oriented institutions controlling society;"7 she states, however, that, "Latin American literature, since independence in the early 1800s, has been, with some exceptions, an instrument for exposing injustice suffered by certain segments of the population and for provoking much needed change."8 Shea's words suggest that Latin American women, themselves oppressed, might tend to write about their own unjust treatment in an effort to stimulate change; Esquivel's work indeed contains elements of this idea.

Gerald Martin treats another aspect of Latin American literature, 
which he calls "the myth"; Martin says this is "the continent's own dominant self-interpretation":

The myth, Romantic in origin, Surrealist in focus, rebellious in orientation, is in essence about the relationship of the New World to the Old. It tells of discovery and conquest .... and of desperate struggles ... to resist, rebel, and liberate .... And it shows how the people's dreams, utopias and occasional triumphs become internalized through folk memory and through art which, sometimes at least, can make itself the written record of that memory, and thus unite past, present and future at the level of representation. 9

Martin applies his concept, which he says is the "writers' collective interpretation of what Latin American history has been about," stating that,

Each writer ... can see the myth as their own individual journey through the labyrinth of life (consciousness, knowledge, memory, morality), history or fiction itself. . . ... Each novel, each fictional construct, is itself a journey through the labyrinth.

The quest for identity, then, has been the central problematic of Latin American culture and the central theme of Latin American literature . . . 10

Again, elements of Martin's "myth" are evident in Chocolate, offering another way in which Esquivel's novel is a part of its Latin American culture.

Rosemary Geisdorfer Feal, who has studied the way in which women authors fit into the Latin American tradition, offers a suggestion that may be applied to Chocolate. She believes that "if anything characterizes 'feminine' narrative, it is the lack of homogeneity; in its place is the radical assertion of individuality, the refusal to belong to a category"; the literature of Latin American women writers, states Feal, "is often forged in isolation and in rebellion."11 Feal's statement suggests a bridge between Esquivel's non-categorizable writing and her neat niche within the tradition of Latin American women writers. Esquivel's unique achievement, which may be examined in terms of its structure, its themes and characterizations, its use of the additionally culture-linked device of magical realism, and its language, emerges as a work that won't be pigeonholed, the strong statement of a suppressed yet powerful voice in a distinctive culture.

I have already addressed Chocolate's genre-bending nature. 
The physical structure of the novel is one feature of the work that supports this idea; Chocolate bears the subtitle "A Novel in Monthly Installments with Recipes, Romances and Home Remedies," and indeed it contains all of the above elements. Glenn summarizes the book's basic layout: "The title page for each of the twelve divisions of the book gives the chapter number, a month of the year, and the name of a recipe." 12 This observation, more perceptive than it appears, immediately demonstrates the blended-genre quality of Esquivel's work; Chocolate is at once a novel, organized by chapters; an almanac, divided by months; and a cookbook, composed of recipes.

The material within each section of the novel, however, seems even more amalgamated and remarkable. The book's first segment, for example, begins, as do the following eleven portions, with a list of ingredients (in this case, for "Christmas Rolls") and the term "Preparation: ..." above the first words of the text. 13 As expected from these cookbooklike introductory elements, the tone of the narration is often impersonal and didactic, with the detached speaker offering rudimentary instructions:

It is best to use homemade rolls. Hard rolls can easily be obtained from a bakery, but they should be small; the larger ones are unsuited for this recipe. After filling the rolls, bake for ten minutes and serve hot. For best results, leave the rolls out overnight, wrapped in a cloth, so that the grease from the sausage soaks into the bread. 14

On either side of paragraphs such as this, though, are personal bits of autobiography from the firstperson narrator ("Mama used to say . . . I was especially sensitive to onions, like my great-aunt, Tita"15), portions of Tita's chronologically-told tale offered in the distant voice of the storyteller ("From that day on, Tita's domain was the kitchen, where she grew vigorous and healthy on a diet of teas and thin corn gruels"16), and dialogue among the "players" in Tita's story (Tita's domineering mother to Tita: "'Baste it and sew it again and then come and show it to me. And remember that the lazy man and the stingy man end up walking their road twice'"17). There is no separation of narrator and the subjects of the narration; all a part of the same extended bloodline, Tita's family, and consequently the narrator's family, both live and impart the main story contained in Chocolate. Likewise, there is no disassociation between cookbook and novel; they are both simultaneous and elaborately interwoven. Anecdotes and household hints are offered in the same figurative breath, and this breath animates both the storyteller and the cook.

Lawless points out that the serialized format, this "presentation" of the work "as monthly installments," is "a popular strategy for enticing 
the reader, often used in Mexican photonovelas and the avidly consumed libros semanales." 18 Glenn concurs with this linking of the novel's form to "popular" fiction by noting that the "overplotting and abuse of coincidence that are found in popular fiction are ... grist for Esquivel's mill"; 19 in fact, "overplotting" seems an understatement when one considers scenes such as the following

\begin{abstract}
She hadn't anticipated Pedro getting captured by the federales and summarily detained from getting the doctor, or Mama Elena and Chencha being unable to return because of shooting breaking out in the village that forced them to take refuge with the Lobos; so it turned out she was the only one present at the birth of her nephew. She! She alone!20
\end{abstract}

This convoluted interweaving of tales is a characteristic of Gothic fiction, as Lawless observes, as is the stifling and untamed setting and the presence of the heroine, her lover, and their tyrannical antagonist;21 Chocolate's possession of these elements further links it with the pop fiction of the Latin American masses. Glenn notes that many nineteenthcentury women's magazines in particular "featured serialized novels, poetry, recipes, and home remedies."22 In this way, Chocolate is aligned not only with its pop cousins but with "women's" literature, as well: "Como agua calls attention to activities customarily considered feminine: the reading of women's magazines, the giving and preparing of recipes, and the sharing of remedies and household hints."23 So Chocolate, with its intriguing internal blend of types, offers an outward mingling as well; elements of popular, Gothic, and women's fiction combine with Esquivel's skillful use of language and thematic elements to produce a work capable of crossing audiencespecific boundaries.

Glenn's linking of the novel with feminine traits suggests a multitude of other possible relationships, one of which relates particularly to Chocolate's structure. Amy Kaminski's study of feminist theory and its relationship to Latin American literature treats the work of Elena Garro and the way in which time in Garro's fiction is portrayed; Kaminski says that the circular nature of time in Garro's work is linked to "the female subject and to the bodily apprehension of time as cyclical," and that this is also a feature of Latin American fiction in general.24 A circular work, according to Kaminski, is one that "ends where it begins," and this concept seems applicable to Esquivel's calendar-based cycle of life, death, and rebirth. Kaminski refers to a "sense of completeness and impermeability" when discussing this phenomenon:

Though the narrative follows a certain chronology insofar as the unfolding of the anecdote is concerned, the 
narrator frequently invokes other moments in time that are equally available, though less or more remote from the assumed present from which it speaks. These other times are evoked not to situate the moment of the anecdote within a greater historical chronology, but, on the contrary, to flatten out the differences between "before" and "after."25

This culture-linked idea of time figures strongly in Esquivel's work. Chocolate opens with Tita's greatniece speaking from a point at least two generations after Tita's own, and a number of years after Tita's death. The story then returns briefly to the months immediately preceding Tita's birth and follows Tita from her auspicious entrance into the world to her death a number of years later. The novel's final paragraph brings the work full circle, returning to the present-time narrator and the narrator's reminiscences about her own mother; as the novel closes, the narrator prepares to make the same Christmas rolls that were offered us in the first chapter, remarking that, "My mama prepared them for me every year."26 The cycle, now complete, will be eternal, the narrator says: "Tita, my great aunt, . . . will go on living as long as there is someone who cooks her recipes."27 This linking of generations lends further support to the idea that all time exists at once, and the arrangement of the death and rebirth ideas suggest the circular concept that dominates Latin American literature.

Glenn observes that, "Recipes, like Proustian madeleines, serve to recuperate the past and thereby expand the time frame of the novel;"28 this idea seems to add to Kaminski's more universal thoughts. We are told by Esquivel's narrator that "smells have the power to evoke the past, bringing back sounds and even other smells that have no match in the present." 29 When Tita and Nacha prepare the filling for Rosaura's wedding cake, they take out a previously-prepared container of preserves: "The moment Tita opened the jar, the smell of apricots transported her to the afternoon they made the marmalade."30 After Tita's crisis, as she recovers at John's ranch, Chencha comes to bring her ox-tail soup made from the recipe of Tita's beloved Nacha:

With the first sip, Nacha appeared there at her side, stroking her hair as she ate, as she had done when she was little and was sick, kissing her forehead over and over. There were all the times with Nacha, the childhood games in the kitchen, the trips to the market, the stillwarm tortillas, the colored apricot pits, the Christmas rolls ... . 31

Thus, the past and the present are incontrovertibly connected, always 
capable of existing in what traditional thought would term the other's realm. In Chocolate, the link, and therefore the story, is the recipe.

As much as Esquivel's genre-blending tactics serve to cross audience lines, though, the author's achievement is not universally iconoclastic; her use of themes and characters fix Chocolate firmly in Esquivel's own Latin American culture.

Earlier I referred to Gerald Martin's impression of the Latin American myth, which he believes appears in the work of individual Latin American authors. We may remember that his conception of the myth involves "discovery and conquest," "struggles," and the "resist, rebel, and liberate" sequence, with Martin stressing that the search for identity is inherent in these themes. In Chocolate, I see two ways in which this pattern reveals itself, the first involving the kitchen as a kind of symbolic space that must be conquered and the second dealing with Tita's oppression, exile, and eventual liberation.

The kitchen in Esquivel's novel is what Glenn terms "gendered space."32 Lawless, too, views the kitchen as significant to the novel and as a gender-specific location, but she provides the added dimension of the kitchen itself as a region of exile in that it is the domain of Tita and the household's Indian servant women, Nacha, Chencha, and Luz: "The kitchen becomes a site for the production of the discourse of the triply marginalized -- the Indian, the servant, the woman." 33 What is important, though, is what ultimately happens to the kitchen and its occupants.

Tita is born in the book's opening chapter "right there on the kitchen table amid the smells of simmering noodle soup, thyme, bay leaves, and cilantro, steamed milk, garlic, and, of course, onion." 34 It is Nacha, "who knew everything about cooking," who becomes completely responsible for Tita's nourishment; therefore, " . . . Tita's domain was the kitchen, where she grew vigorous and healthy on a diet of teas and thin com gruels .... Her eating habits ... were attuned to the kitchen routine. ..."35 It may seem, then, that Tita's conquest of the significant territory in Esquivel's novel is not an issue; however, Lawless' comments about the marginalized nature of the kitchen's inhabitants become significant here. Although Tita has immediately discovered the new world, so to speak, the novel is the story of her struggles to conquer, or master, it.

For Tita, while the kitchen is initially a place of refuge, it serves, too, as the kind of no-man's land that Lawless suggests. Tita is "forbidden to play with her sisters in her own world," 36 suggesting that the kitchen is a less than desirable location; she is similarly relegated to the kitchen to prepare Rosaura and Pedro's wedding feast "as punishment." 37 When Nacha dies, it is Tita, the black sheep and most marginal member of the family, who is named "to fill the vacant post in the kitchen." 38 And when Tita arrives at John's house, she encounters another kitchen with another outsider ("Katy, a seventy-year-old North American woman") in charge.39

Gradually, though, Tita turns the kitchen into more than a safe 
haven; as Lawless observes, she "converts this traditionally restrictive and oppressed site for women into a liberating, creative space . . ."40 Some of this has been hinted at since the novel's first page; we are told, for instance, early in the work, that, "for Tita the joy of living was wrapped up in the delights of food." 41 Yet Tita goes further, using the kitchen as a place for rebellion and resistance. She furtively nurses her nephew, Rosaura and Pedro's infant son, in the kitchen.42 She and Pedro use the room for their illicit meetings (see, for instance, the examples of Pedro's encounter with Tita moments after he becomes engaged to Rosaura43 and of Tita and Pedro's meeting over the grinding stone44). She creates things in the kitchen that allow forbidden acts to take place; her preparation of quail in rose petal sauce, for instance, allows for a sort of surreal lovemaking to occur between Tita and her sister's husband:

It was as if a strange alchemical process had dissolved her entire being in the rose petal sauce, in the tender flesh of the quails, in the wine, in every one of the meal's aromas. That was the way she entered Pedro's body, hot, voluptuous, perfumed, totally sensuous. 45

In a significant scene, the kitchen becomes occupied, at Tita's request, by her cigarette-smoking, wild and wayward sister, now a general in the revolutionary army, and Gertrudis' womanizing sergeant.46 Working together and following Tita's instructions, Gertrudis and Trevino, both previously inept cooks, simultaneously prepare a tremendously successful batch of cream fritters and transform the kitchen from a refuge for society's outcasts into a fertile place where anything is possible.

Lawless says that Chocolate "confers a higher status and power to the traditionally devalued personal sphere of the kitchen," stating that, "A new terrain appears in Chocolate . . ."47 This seems akin to the conquest of the new terrain of which Martin speaks, and it is in this realm where Tita discovers her identity.

Approached another way, though, Tita represents the oppressed portion of Latin American society that Maureen Shea discusses and that I considered in the early pages of this study. Tita is controlled by the cruel Mama Elena, whose dictatorial and merciless ways make Tita's life oppressive and miserable, and by the archaic traditions of the society, relentlessly enforced by Mama Elena, which add the element of hopelessness to Tita's existence. Because she is the family's youngest daughter, Tita's fate is sealed, as Mama Elena reminds her, "If he intends to ask for your hand, tell him not to bother. He'll be wasting his time and mine too. You know perfectly well that being the youngest daughter means you have to take care of me until the day I die."48 Mama Elena and this tradition are responsible for the fact that Tita cannot marry her beloved Pedro; when Pedro marries 
Rosaura, then, tradition, in the form of her mother, is the real culprit against which Tita must rebel. Her struggle occupies the entire novel.

Amy Kaminski, in her discussion of the works of other Latin American women writers, identifies a "conundrum of political exile":

Once the narrator has entered the contest, played, and lost, she must leave, for she has heard that unspeakable things happen to those who lose and remain. Banished, she circles the house and discovers its real shape .... Only by leaving could she learn the shape of the house ... 49

Kaminski says that the "female exile is empowered with extrahuman capacities" which involve "transcendence and regeneration."50

Chocolate fits neatly into Kaminski's conceptualization of the liberated female exile. When Tita finally rebels against Mama Elena, she immediately leaves the ranch house, Mama Elena's domain, and retires to the dovecote, where she returns to an embryonic state; when Dr. Brown arrives, he finds her "naked" and "curled up in a fetal position."51 John takes her to his own home, where she resides, refusing to speak. It is only the presence of the other "outcasts" (John's North American cook, the mysterious Indian woman in the garden who reminds Tita of Nacha, and finally Chencha, with her healing pot of ox-tail soup) that restores Tita to health. Thus, Tita learns the truth about her life, Kaminski's "shape." She realizes that her life force is to be found in the very things her own society shuns; from this point, then, Tita may go about the business of discovering and establishing her own identity. Only in her exile is Tita liberated.

In the novel's initial chapter, as the story of Tita's birth is related, we learn that Tita is "literally washed into this world on a great tide of tears that spilled over the edge of the table and flooded across the kitchen floor"; after the water dries up, Nacha sweeps up the "residue": "enough salt to fill a ten-pound sack." 52 Glenn sees this scene as "a good example of Esquivel's flaunting of the inverisimilitude of her narrative," stating that this episode and others like it "warn us that what follows cannot be accepted at face value."53 I believe, however, that Glenn misunderstands Esquivel's use of what is a staple of the Mexican narrative; Esquivel uses the traditionally Latin American device of magical realism to illustrate particular elements of the story, aspects which may be viewed as examples of the "extrahuman" capacities of Kaminski's female exile. Ross Larson identifies magical realism as a portrayal of supernatural and fantastic events and elements "in a matter-of-fact way, combining reality with fantasy for a representation of the world that is not uncanny but essentially true";54 Larson suggests that this device may be "an author's means of communicating a deeply personal, even a 
visionary experience of reality," 55 and this view seems applicable to Chocolate.

When Tita's birth yields the tremendous quantity of salt, enough to use for cooking "for a long time,"56 Esquivel foreshadows Tita's great contribution to the culinary arts and the way in which she will add flavor to her own life and the lives around her. Rosaura and Pedro's wedding cake, flavored with Tita's own tears, causes each member of the wedding party to become fiercely ill57; this effect demonstrates the power of sadness, just as Tita's miraculous ability to nurse her nephew58 suggests the power of love. Food takes on the ability to heal and to act as an aphrodisiac.59 In these ways, Esquivel presents reality in her own way, using fantasy-like elements to emphasize and interpret the incidents in the novel to which she wishes to draw attention. Chocolate, in addition to addressing the cultural myths of the Latin American society to which its author belongs, places some reliance on traditionally Latin American devices in order to achieve its goals.

Esquivel's loyalty to the dominant ideas of her culture (Martin's myth, and, somewhat secondarily, Kaminski's) is evident in her novel. Esquivel chooses not to be bound by genre and by canonical definitions of audience-specific guidelines, but she embraces the powerful material her own culture has to offer. Her unique interpretations of these elements comprise a large portion of her achievement. The inventive use of language in Chocolate, however, is Esquivel's own.

Esquivel constructs an elaborate system of metaphors and word equations in Chocolate. Food is the controlling motif, and it is used as a point of comparison for Tita herself time and time again. When Tita hears that Pedro will marry Rosaura, her cheeks turn "red as the apples beside her."60 A glance from Pedro makes her aware of "how dough feels when it is plunged into boiling oil."61 Tita is "broken in both heart and in mind" by Pedro's marriage to Rosaura, "like the quail" whose neck she twists before cooking.62 When she is "lost and lonely," she feels that, "One last chile in walnut sauce left on the platter after a fancy dinner couldn't feel any worse than she did,"63 and she relates to "the odd, detached way a lettuce should feel at being separated abruptly from another lettuce with which it had grown up."64 The novel's title is explained when we are told that "Tita was literally 'like water for chocolate' -- she was on the verge of boiling over."65

Food is Tita herself, then, and literally the life-force in Chocolate. Tita's beloved nephew Roberto is born with a head "shaped like a cone of brown sugar," and within minutes he is "[w]rapped up like a taco"66; he allows Tita her one foray into motherhood, literally making her his mother when she begins to produce milk to feed him. Rosaura, a major party to Tita's inability to create a life with the man she loves, is alienated from the start because of her attitude toward food; we learn that it is "Rosaura's picky eating" and her tendency to leave "her food untouched 
on her plate" that provoked both the nurturing Nacha's dislike of Rosaura and the rift between the sisters.67 Finally, Mama Elena, the cartoon-like villain who embodies the most strongly anti-life force in Tita's world, literally perishes from starvation; unable to receive nourishment, she ingests a quantity of ipecac, "a very strong emetic that could cause death."68

Similarly, Esquivel uses the metaphor of light and fire to represent sexuality and love, thus offering a different route to her vital spark. A primary example of this equation is offered in John's lecture to Tita on match-making. John explains that phosphorus united with oxygen will "burst into flame very rapidly at an elevated temperature," and he demonstrates this phenomenon by mixing the two elements; when he does so, "an explosion occurred, brilliant, instantaneous, like a flash of lightning." $69 \mathrm{He}$ follows his presentation with the information that "within our bodies each of us has the elements needed to produce phosphorous"; he relates a theory touted by his grandmother, another of the novel's wise Indian figures, that depicts the necessary oxygen as "the breath of the person you love" and the needed warmth as "any kind of food, music, caress, word, or sound . . . ."70

Tita has epitomized this metaphor prior to John's story. When Pedro and Rosaura announce their betrothal, she is gripped with "an icy feeling of grief," a "terrible sensation of cold" that no amount of covering and wrapping can cure.71 On the other hand, when Tita and Pedro are near each other, there is a "spark" between them;72 Tita feels that the "heat that invaded her body" because of Pedro's glance "was so real she was afraid she would start to bubble."73

When "[f]or the first time in their lives, Tita and Pedro could make love freely," Pedro lights "250 candles" in a "now inappropriately named dark room." As the couple consummate their lifelong love, Pedro dies, and with him dies the "possibility of ever again lighting" Tita's "inner fire"; immediately Tita begins to experience a "freezing chill." In an effort to warm herself, she begins to devour a box of candles, thus uniting Esquivel's two metaphoric sources of vitality; as Tita remembers Pedro, "the candle began to burn" and Tita joins her lover in "the lost Eden":

At that moment the fiery bodies of Pedro and Tita began to throw off glowing sparks. . . The dark room was transformed into an erupting volcano. It cast stone and ash in every direction. When the stones reached high enough, they exploded into multicolored lights. From miles away, people in neighboring towns watched the spectacle, thinking it was fireworks . . . .74

Thus, at Chocolate's end, Esquivel's key images are united in a dramatic, vital flourish. We are told that under the layers of ash that 
blanket the former site of the ranch house "every kind of life flourished, making this land the most fertile in the region."75 Food, lovemaking, and fire are drawn together in a climatic display of pageantry that is the life force of Esquivel's world.

Glenn points out that "[t]he association of fire and passion has been made so often in literature and art as to have become commonplace";76 indeed this seems a reasonable observation. Glenn goes on, however, to maintain that "the passion felt by Tita and Pedro ignites the bed on which they lie, and the ensuing conflagration reduces the ranch to ashes. Their love is, indeed, all-consuming."77 Here I must take exception to Glenn's analysis. A careful study of the metaphors and their function in Esquivel's work shows that food, fire, and love are not destructive but rather life-affirming and life-producing, in fact life itself. Esquivel's use of cliché must be examined alongside the use of her own unique equations; Chocolate's meaning is found here.

Lawless points out that "[t]he only thing that remains of Tita after the fire is a cookbook from which her great-niece reconstructs and narrates Tita's story. Again . . . the written word resists destruction."78 This brings up an interesting connection between food and love and language itself, prompting Lawless to remark that, "In Chocolate, terms such as 'cookbook,' 'gothic, 'feminine,' 'home' are redefined and remolded in Esquivel's (post)modern attempt to create a place from which her character Tita can speak."79 Thus, this study has come full circle, returning to the idea of Esquivel's genre-defying and border-crossing novel of mass appeal.

Like Water for Chocolate seems to be in continuous motion, appearing now as a popular novel replete with clichés and soap-opera characters, now as a manifesto of Latin American thought offering powerful messages of exile and independence, now as a multi-faceted work of fiction deserving of critical attention. Esquivel surprises us with bursts of brilliance in particular turns of phrase, reassures us with formula, and enlightens us with combination. Chocolate is sustaining and nourishing, food for thought, bread for the hungry, refreshment for the jaded: Esquivel is generous with all.

\section{NOTES}

1 Cecelia Lawless, "Experimental Cooking in Como agua para chocolate," Monographic Review 8 (1992): 261-72; Kathleen Glenn, "Postmodern Parody and Culinary-Narrative Art in Laura Esquivel's Como agua para chocolate," Chasqui 23 (November 1994): 39-47.

2 Lawless, 261.

3 Lawless, 263. 
4 Glenn, 46

5 Glenn, 40.

6 Amy K. Kaminski, Reading the Body Politic: Feminist Criticism and Latin American Women Writers

(Minneapolis: University of Minnesota Press, 1993), 28-9.

7 Maureen E. Shea, "Latin American Women and the Oral Tradition: Giving Voice to the Voiceless," Critique 34 (Spring 1993), 142.

8 Shea., 140.

9 Gerald Martin, Journeys Through the Labyrinth: Latin American Fiction in the Twentieth Century (New York: Verso, 1989), 8-9.

10Martin., 50-1.

11Rosemary Geisdorfer Feal, "Women Writers into the Mainstream: Contemporary Latin American Narrative," in Philosophy and Literature in Latin America, Jorge J.E. Garcia and Mireya Camurati, eds. (Albany, NY: SUNY Press, 1989), 120.

12 Glenn, 41.

13Laura Esquivel, Like Water for Chocolate, trans. Carol Christensen and Thomas Christensen (New York: Doubleday, 1992), 2-3.

14Esquivel, 12-13.

15Esquivel, 3.

16Esquivel, 5.

17Esquivel, 10-11.

18Lawless, 263.

19Glenn, 44.

20Esquivel, 69.

21Lawless, 262. 
Ethnic Studies Review Vol. 19, No. $2 \& 3$

22Glenn, 41.

23Glenn.

24Kaminski, 79-80.

25Kasminski, 80.

26Esquivel, 241.

27Esquivel.

28Glenn, 45.

29Esquivel, 7.

30Esquivel, 29.

31Esquivel, 120.

32Glenn, 41.

33Lawless, 264.

34Esquivel, 4.

35Esquivel, 5.

36Esquivel, 6.

37Esquivel, 25.

38Esquivel, 44.

39Esquivel, 104.

40Lawless, 267.

41Esquivel, 5.

42Esquivel, $76 \mathrm{ff}$.

43Esquivel, $16 \mathrm{ff}$.

44Esquivel, 64ff. 
45Esquivel, 48.

46Esquivel, $181 \mathrm{ff}$.

47Lawless, 268.

48Esquivel, 9.

49Kaminski, 36.

50Kaminski, 38.

51Esquivel, 97.

52Esquivel, 4.

53Glenn, 44.

54Ross Larson, Fantasy and Imagination in the Mexican Narrative (Tempe, AZ: Arizona State University Press, 1977), 99.

55Larson, ix.

56Esquivel, 4.

57Esquivel, 37ff.

58Esquivel, 74ff.

59Esquivel, 48ff, 120ff, 235ff.

60Esquivel, 13.

61Esquivel, 14.

62Esquivel, 45.

63Esquivel, 54.

64Esquivel, 132.

65Esquivel, 147.

66Esquivel, 71. 
Ethnic Studies Review Vol. 19, No. 2\&3

67Esquivel, 28.

68Esquivel, 132.

69Esquivel, 111.

70Esquivel, 111-12.

71Esquivel, 17-18.

72Esquivel, 78.

73Esquivel, 14.

74Esquivel, 237-40.

75Esquivel, 241.

76Glenn, 43.

77Glenn.

78Lawless, 268.

79Lawless, 270. 